\title{
16. 臨床応用を目的とした小児用補助人工心蔵の開発
}

\author{
妙中義之* 高野久輝* 中谷武柌* \\ 梅津光生*田中隆*松田武久* \\ 岩田博夫* 野田裕幸* 阿久津哲造*
}

\section{1. 研究目的}

成人例之同様に，小少の開心術後重症心不全 例の中にも IABP や V-A バイパス法等のこ れまでの補助循環法の限界を越えた症例がみら れる。 また小坚例に対する IABP は, 大動脈 径に比べて末梢動脈が細く, 十分な大きさのバ ルーンが挿入しにくいこと, 大動脈壁の弾性が 大きいこと等の小児の特徴によりその効果は満 足すべきものではない. $\mathrm{V}-\mathrm{A}$ バイパス法も使 用時間の制限, 出血傾向等の合併症の発生の点 で問題が多い，一方われわれは先天性心疾患の 開心術後重症心不全に対しても補助人工心臟が 有力な治療手段と成り得ることを動物実験等で 確認して報告してきた. 今回の研究の目的は小 児例に対しての使用を目的として開発してきた 小児用補助人工心臟の in vitro および in vivo の性能評価をすることである.

\section{2. 小児用補助人工心臓の概要}

基本的には成人用のものを小型化したそデル であり，問題があれば，デザインを変更する方 針で製作した，小児に使用するためには，従来 の成人用のものでは容量が大きすぎ，抗血栓性 に大きな影響がある血液の wash-out の点で 問題があり, 小型化が必要と考えられた。 そこ で 1 回拍出量 $40 \mathrm{ml}$ の M型と, $20 \mathrm{ml}$ の $\mathrm{S}$ 型 の 2 種類の空気圧駆動ダイアフラム型のポンプ を製作したが，今回は主に S 型のポンプについ て検討を行った．材料は抗血栓性と耐久性に優 れたセグメント化ポリウレタン（東洋紡製 TM シリーズ）を用い，流入出口にそれぞれ BjorkShiley \#21を有している. また小贸に対して の装着の容易さを考慮して, conduit は内径

* 国立循環器病センター研究所

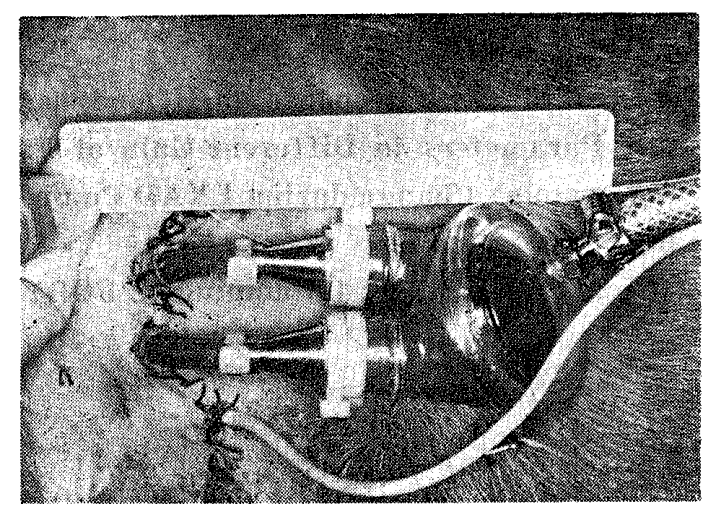

Fig. 1 The S-size VAD

$6 \mathrm{~mm}$ と $8 \mathrm{~mm}$ のものを用いることとした (Fig. 1).

\section{3. 実験方法}

1) in vitro の性能評価

オーバフロータンクを用いて, 流入圧 10 $\mathrm{mmHg}$, 流出圧 $80 \mathrm{mmHg}$, 駆動圧 $200 \mathrm{mmHg}$, 陰圧 $-50 \mathrm{mmHg}$ の条件で, 拍動数と収縮時 間 (\%-systole) を変更し, それに伴う拍出量 の変化を測定した. conduit の長さは $150 \mathrm{~mm}$ とした。

\section{2) in vivo の性能評価}

慢性実験として S 型の小兄用補助人工心臓を 体重 $9 \mathrm{~kg} \sim 17 \mathrm{~kg}$ の仔ヤギの左房一下行六動脈 間に装着して検討を行った. 4 頭は 1 力月生 存, 1 頭は 2 力月生存を目標として実験を行 、, 主に耐久性, 抗血栓性, 幼若動物に対する 影響等を中心に検討した．なお抗凝血療法とし ては, ヘパリンを補助人工心臓装着直前に $3 \mathrm{mg} / \mathrm{kg}$ 投与するのみとし, 術後は一切行わな かった。

\section{4. 実験成續}

1 ) in vitro の性能評価

内径 $8 \mathrm{~mm}$ の conduit を用いた場合, 拍動 

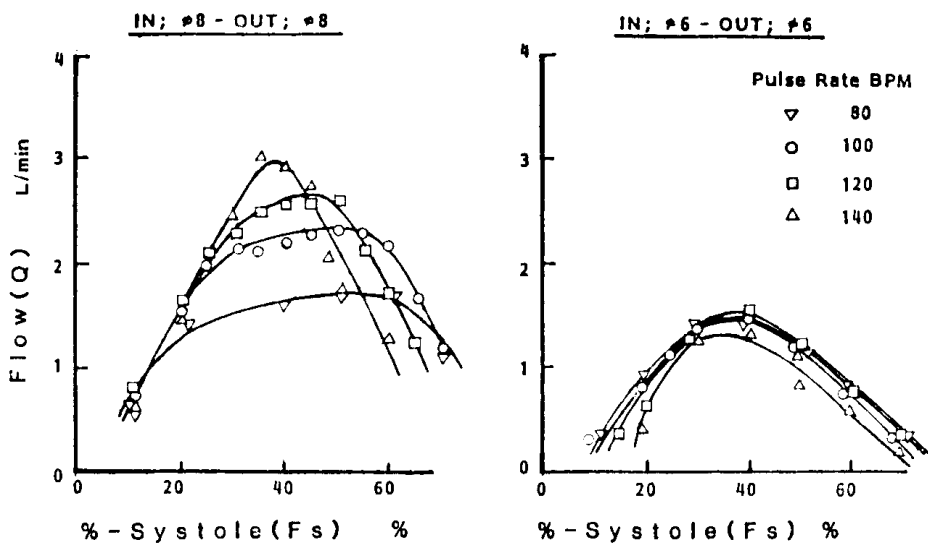

Fig. 2 Relationship between Pump Flow \& \%-Systole $\left[\begin{array}{l}P \text { in } ; 10 \mathrm{mmHg}, \text { DP }: 200 \mathrm{mmHg} \\ P \text { out } ; 80 \mathrm{mmHg}, \text { DV }:-50 \mathrm{mmHg}\end{array}\right] \begin{array}{r}\text { (Pump : S-type) } \\ \text { [NCVC] }\end{array}$

数 $80 /$ 分 $140 /$ 分, $\%$-systole $35 \%$ - $60 \%$ の 条件で, 最大 $1.8 \mathrm{~L} /$ 分 $3.1 \mathrm{~L} /$ 分の 拍出量を 得ることができた。一方, 内径 $6 \mathrm{~mm}$ の conduit では, 今回のような駆動圧, 陰圧を一定 にした条件では拍動数による差はほとんどな <，拍動数 80/分～140/分， \% - systole $40 \%$ 前後の条件で, 最大約 $1.5 \mathrm{~L} /$ 分の拍出量を維持 し得た (Fig. 2).

2 ) in vivo の性能評価

すべての動物に执いて左房内への inlet conduit の挿入, 大動脈への outlet conduit の縫 着は容易であった. 1 力月生存の 4 頭は犠死せ しめるまでの間元気に生存した. case 3 は 28 日目に outlet conduit の内腔の狭窄を疑って 犠死させたが，解剖したところ, outlet の人工 血管内の偽内膜が異常增殖するという稀な合併 症が発生していた。 case 4 は 2 力月生存実験 で，71日目に塞栓症を発生する以前にはポンプ 内に血栓形成などは認めなかった。これも解剖 したところ，実験期間中に体重が $16 \mathrm{~kg}$ から $23 \mathrm{~kg}$ 汇増加したために人工血管が電磁流量計 プローブ装着部位で屈曲して㧍り, 同部から発 生した塞栓が原因と考えられた。 バイパス流量 は低流量での抗血栓性を検討する目的で, 流量 を0.3L/分 0.5L/分に固定した case 5 を除 いて, $0.7 \mathrm{~L} /$ 分 $1.7 \mathrm{~L} /$ 分を維持することがで きた。

耐久性に関してはポンプ，人工弁，駆動装置 等の破損は一度名経験しなかった。抗血栓性に
Table. 1 Results of the Chronic Experiment

\begin{tabular}{|c|c|c|c|c|}
\hline $\begin{array}{l}\text { Case } \\
\text { No. }\end{array}$ & $\begin{array}{l}\text { Body } \\
\text { Weight } \\
\text { (kg) }\end{array}$ & $\begin{array}{l}\text { Bypass } \\
\text { Flow } \\
(L / \text { min })\end{array}$ & $\begin{array}{l}\text { Pumping } \\
\text { Duration } \\
\text { (days) }\end{array}$ & $\begin{array}{l}\text { Cause of } \\
\text { Termination }\end{array}$ \\
\hline 1 & 14 & $0.8--1.3$ & 33 & electively sacrificed \\
\hline 2 & 17 & $1.2-1.7$ & 36 & electively sacrificed \\
\hline 3. & 12 & $\begin{array}{l}0.7-1.2 \\
(\rightarrow 0.2)\end{array}$ & 28 & $\begin{array}{l}\text { sacrificed } \\
\text { (stenisis of outflow graft) }\end{array}$ \\
\hline 4 & 16 & $1.0-\cdot 1.5$ & 71 & $\begin{array}{l}\text { embolism from } \\
\text { kinked outflow graft }\end{array}$ \\
\hline 5 & 9 & 0.30 .5 & 34 & electively sacrificed \\
\hline
\end{tabular}

ついては，当初，人工并周囲の血栓形成を経験 したが，人工弁とハウジングの間の fitting を 改善して以来, 問題はなくなった。

低流量で観察した case 5 では犠死後ポンプ 内红 $2 \mathrm{~mm} \times 3 \mathrm{~mm}$ < $2 \mathrm{~mm} \times 4 \mathrm{~mm}$ の 2 つ 小血栓を認めたが，弁周囲には異常を認めなか った (Table 1)。血清 GOT, GPT は術直後に 上昇，尿素空素は減少したが 1 週目以後術前值 に回復した．総ビリルビン，クレアチニン，血 墏フリーへモグロビン変化を示さなかった (Fig. 3).

\section{5. 総 括}

in vitro の性能評価の結果から考えると， S 型の補助人工心臟は，身体の小さい小児に対し ては内径 $6 \mathrm{~mm}$ の conduit を用い，より大き な小児に対しては内径 $8 \mathrm{~mm}$ の conduit を使 用することで，装着の容易さと十分な拍出量の 維持の両面をカバーし得ると思われた，また頻 

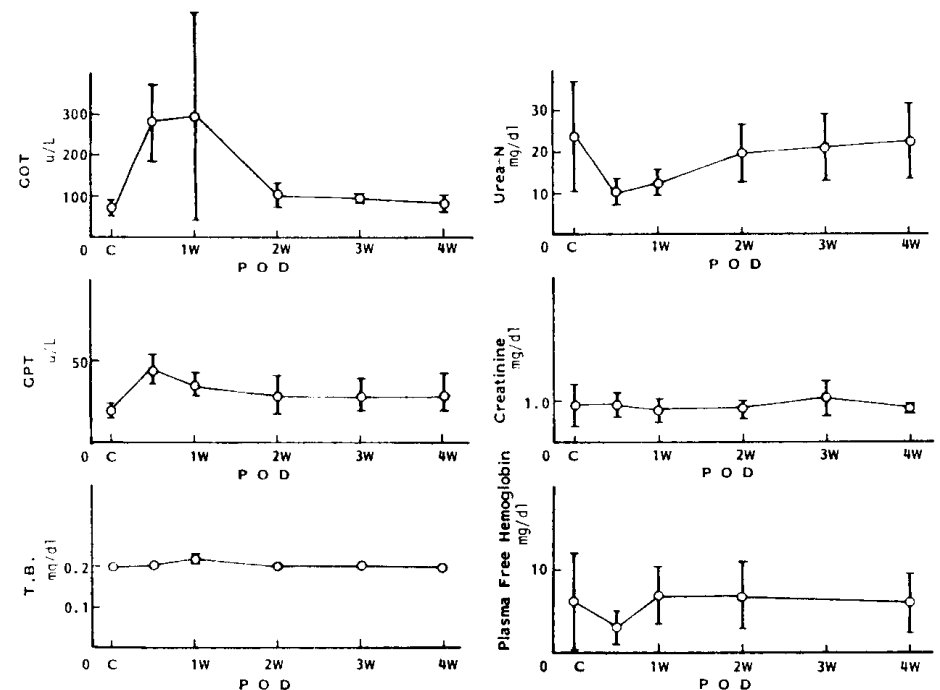

Fig. 3 Profiles of Blood Chemistry during Pumping in Young Goats

脈に対する良い追従性は，心不全時の補助に際 して有効と考えられる counterpulsation を行 う上で有利である。

慢性実験により, 装着の容易さ, 十分な流量 維持能力, 良好な耐久性扝よび抗血栓性, 血液 生化学データよりみた幼若動物への影響の無さ 等が証明された。抗血栓性に関しては，流量を 初期から $0.7 \mathrm{~L} /$ 分以上維持することができれば 抗凝血療法なしでも問題はないが， $0.5 \mathrm{~L} /$ 分前 後より少なくなればへパリン投与等の抗凝血療 法を行っておいた方が，より安全であると思わ れた。

\section{6. 結 論}

開発した $S$ 型小巟用補助人工心臟は, in vitro 拉よび in vivo 評仙で, 小睍用としての優 秀な性能を示し， 1 力月前後の使用であれば臨
床への応用も可能であると考えられた．

\section{参考文献}

1）近江三喜男 他：幼海開心術後の重篤な心不全 に対寸る IABP の使用経験, 胸部外科 36 巻 1 号: 57, 1983

2) Pollock J.C. : Intraaortic Balloon Pumping in Children, Ann. of Thorac. Surg. Vol. 29 : 522, 1980

3）妙中義之 他：右心バイパス術後低心拍出症候 群に対する左心側補助人工心臟の効果の検討, 人工臟器 11 巻 $: 397,1982$

4）妙中義之 他：高度右心不全に対寸る右心側補 助人工心臟の効果に関する実験的検討, 第35回 胸部外科学会総会

5）妙中義之 他：小児用補助人工心臟の試作と性 能評価及び適用症例の検討: 人工臓器13(1), 241,1984 